\title{
Speed Sensorless Control for Permanent Magnet Synchronous Motors Based on Finite Position Set
}

\author{
Xiaodong Sun, Senior Member, IEEE, Junhao Cao, Gang Lei, Member, IEEE, \\ Youguang Guo, Senior Member, IEEE, and Jianguo Zhu, Senior Member, IEEE
}

\begin{abstract}
This paper presents a novel method for the sensorless control of interior permanent-magnet synchronous motors. An iterative search strategy based on dichotomy is proposed to provide a finite number of rotor position angles with good accuracy. These position angles are used to calculate the back electromotive force (EMF) in $d$-axis. The optimal rotor position angle is the one that yields a back EMF minimizing the defined cost function. With the increase of the iterations, the accuracy of rotor position angle increases geometrically. To effectively extract the back EMF signal under the low-speed condition, the high-frequency signal injection method is used to realize the low-speed operation of the motor. A hybrid control strategy is adopted to achieve the smooth switching from the low-speed to high-speed. The performance of the proposed method has been validated experimentally and compared with that of the conventional phase locked loop under different conditions.
\end{abstract}

Index Terms-Iterative search strategy, permanent magnet motors, phase locked loop, sensorless control.

\section{INTRODUCTION}

\section{A. Motivation}

$\mathrm{T}$ HANKs to the features of high efficiency, high power density and fast control response, permanent-magnet synchronous motors (PMSMs) have been widely adopted in

Manuscript received March 11, 2019; revised June 12, 2019 and September 8, 2019; accepted October 9, 2019. This work was supported by the National Natural Science Foundation of China under Project 51875261, the Natural Science Foundation of Jiangsu Province of China under Projects BK20180046 and BK20170071, the "Qinglan project" of Jiangsu Province, the Key Project of Natural Science Foundation of Jiangsu Higher Education Institutions under Project 17KJA460005, the Six Categories Talent Peak of Jiangsu Province under Pro-ject 2015-XNYQC-003, and the Postgraduate Research \& Practice Innovation Program of Jiangsu Province under Project SJCX19_0574. (Corresponding author: Gang Lei.)

$X$. Sun and J. Cao are with the Automotive Engineering Research Institute, Jiangsu University, Zhenjiang 212013, China (email: xdsun@ujs.edu.cn, caojunhaoujs@163.com).

G. Lei and Y. Guo are with the School of Electrical and Data Engineering, University of Technology Sydney, NSW 2007, Australia (email: Youguang.Guo-1@uts.edu.au, Gang.Lei@uts.edu.au).

J. Zhu is with the School of Electrical and Information Engineering, University of Sydney, NSW, 2006, Australia (e-mail: jianguo.zhu@sydney.edu.au). electric vehicles [1]-[5]. Field-oriented vector control has been widely employed to improve the dynamic performance of PMSMs. In order to achieve a high-performance control system, accurate rotor position and speed information are required. However, the installation and use of mechanical sensors will not only increase the system cost, volume and complexity of the drive system, but also reduce the reliability and robustness of the system [6]-[8]. Therefore, a number of sensorless control methods have been developed for the PMSMs to overcome the disadvantages of installation of a position sensor.

\section{B. Related Research}

The sensorless control uses a certain control algorithm to estimate the rotor position and speed by detecting the relevant electrical signals in the motor windings. It has attracted much attention due to its advantages compared with the conventional sensor-based control strategies.

The PMSM sensorless control technique based on the fundamental mathematical model depends on the rotational speed related quantities, e.g., the generated back electromotive force (EMF), in the mathematical model for the estimation of rotor position and speed. Currently, commonly used algorithms include sliding mode observer algorithm, model reference adaptive control algorithm, extended Kalman filter algorithm, and so on [9]-[19]. In this type of control technology, due to the simplicity of phase locked loop (PLL), the back EMF-based PLL observers have been intensively studied for sensorless control technique [20]-[22]. PLL position estimation based on conventional sliding-mode observer algorithm has been proposed to improve the performance of position estimation [21], [22]. Improved methods for estimating back EMF have been proposed [23]. The position error signal in a PLL system is normally processed by a fixed gain proportional-integral (PI) controller to obtain an estimated rotor position or speed [9][23]. However, it requires a large number of tests to tune the PI controller. Additionally, a fixed-gain PI controller may not guarantee the required dynamic performance due to continuing changes of machine parameters, operating conditions and nonlinearities in the inverter. In [24], a simplified convex optimization-base position estimation scheme has been presented for interior permanent-magnet synchronous motor 
(IPMSM) drives, which can be applied to both high speed and low speed operations. It is a creative sensorless control method, which essentially solves a cost function with respect to the rotor position and speed.

Research on model predictive control (MPC) provides another way to estimate the position information based on PLL. The finite control set-model predictive control (FCS-MPC) strategy uniformly takes into account the discrete switching characteristics of the inverter and the nonlinear characteristics of the motor system [25]-[30]. The classical FCS-MPC strategy takes the switching signal of the inverter as the control action, which is not constrained by the converter modulation strategy. During the discrete control period, FCS-MPC solves the openloop optimization problem in the finite time domain online based on the current output measurement value of the controlled object or the observed state variables, while limits the control input set to a finite number of switches combination of the inverter. It has been widely used in the AC motor drive system of matrix converter, multi-level inverter, two-level inverter and other converters, which embodies a powerful versatility and practicality [31]-[35]. In [15], a novel predictive model reference adaptive system (MRAS) rotor speed estimator has been proposed for sensorless induction machine (IM) drives based on the FCS-MPC principle. It is a creative method for sensorless control of IM drive system, which eliminates the need for a PI controller in the adaptation mechanism. In [36], a similar FCS-PLL method is presented for encoderless control of a permanent magnet synchronous generator (PMSG) in variable-speed wind turbines, which is innovative for sensorless control of PMSGs without fixed-gain PI controller. In [37], a MPC with constant switching frequency based on field programmable gate array (FPGA) implementation was proposed for PMSM control. A dichotomy-based cost function optimization algorithm was presented, which can dynamically select the optimization output voltage vector in the control region in a short time.

However, the signal-to-noise ratio of back EMF is low when the motor runs at zero speed and very low speed. Consequently, it is often difficult to extract the relevant electrical signals effectively. The dependence on fundamental excitation ultimately leads to the failure of such methods to detect rotor position and speed at zero speed and low-speed operation.

In order to obtain accurate rotor position information for all speed ranges, the control methods of high-frequency signal injection have been adapted. The basic idea is to superimpose a high-frequency voltage (or current) signal on the fundamental signal and apply it to the winding of the motor [38]-[41]. Thus, the corresponding high-frequency current (or voltage) will carry the rotor position information, and the current (or voltage) signal is extracted through a band-pass filter for proper processing to estimate the position of the rotor. Currently, the high-frequency signal injection methods commonly used mainly include the rotating high-frequency voltage signal injection and the pulse high-frequency voltage signal injection. As to the rotating high-frequency voltage injection method, it is mainly used for the rotor position detection of the IPMSM with a large salient ratio [38], [39], while the pulse high-frequency voltage signal injection method can be used for the rotor position detection of the surface-mounted permanent magnet synchronous motor (SPMSM) with a small salient or even hidden type [40], [41].

Hybrid control strategy in the transition region is necessary to combine the low-speed signal injection control method with the high-speed finite-position set control method. In [42], a hybrid sensorless controller combining the signal injection technique and a linearly compensated flux observer was proposed, which exhibits high performance over the whole speed range including the standstill mode. In [43], a hybrid observer structure for deriving the estimated rotor angle was presented, which implements a smooth transition from a nonmodel-based signal-injection method at low speed to a model-based flux observer at higher speeds.

\section{Contributions}

The method of high-frequency rotating voltage injection will be applied to estimate the rotor position and speed of the investigated IPMSM at low speed in this work. Furthermore, a method based on weighting function is used to calculate the rotor position and speed in the transition region.

In this paper, a novel finite position set PLL based on FCSMPC is proposed for the sensorless field-oriented control (FOC) of an IPMSM, in which the conventional PLL with the fixed-gain PI controller is replaced by the proposed PLL. The main contributions of this paper are listed as follows.

1) An iterative search strategy based on dichotomy is proposed to give a finite number of rotor position angles with reasonable accuracy, which are used to calculate back EMF in $d$-axis. The rotor position angle, whose value of back EMF minimizes the defined cost function, is chosen as the optimal rotor position angle. Then, the change in the rotor position over the sampling time is calculated to compute the rotor speed. Compared with existing search strategy, the proposed method requires a smaller computational burden.

2) A method based on weighting function is used to calculate the rotor position and speed in the transition region, which is applied to compensate and expand the high-speed sensorless control based on finite position set, and realize the combination with low speed control.

\section{Paper Organization}

The remainder of this paper is organized as follows. Section II describes the motor model and presents the method of highfrequency rotating voltage injection for sensorless control of IPMSM at low speed. In Section III, the structure of the conventional PLL is presented and the proposed PLL method based on the feature of FCS-MPC is introduced for sensorless control of IPMSM at medium and high speed. Section IV presents the hybrid control strategy in the transition region. The experimental results for the proposed PLL and hybrid control strategy are presented in Sections V and VI, respectively, followed by the conclusion. 


\section{LOW-SPEED MODELING AND CONTROL OF IPMSMS}

The nonlinear dynamic model of IPMSMs in $d q$-axis reference rotor frame can be described as

$$
\left\{\begin{array}{l}
u_{s d}=R_{s} i_{s d}+\frac{d}{d t} \psi_{s d}-\omega_{e} \psi_{s q} \\
u_{s q}=R_{s} i_{s q}+\frac{d}{d t} \psi_{s q}+\omega_{e} \psi_{s d}
\end{array} .\right.
$$

The flux linkage equation is

$$
\left\{\begin{array}{l}
\psi_{s d}=L_{d} i_{s d}+\psi_{f} \\
\psi_{s q}=L_{q} i_{s q}
\end{array}\right.
$$

where $u_{s d}, u_{s q}, i_{s d}, i_{s q}, L_{d}$, and $L_{q}$ are the $d$ - and $q$-axis components of the stator voltage, current, and inductance in the rotor reference frame, respectively. $R_{s}$ and $\psi_{f}$ are the stator resistance and the magnetic flux of the IPMSM, respectively. $\omega_{e}$ is the electrical angular speed of the rotor.

Transforming (1) to the stationary reference frame as follows

$$
\left[\begin{array}{l}
u_{s \alpha} \\
u_{s \beta}
\end{array}\right]=R\left[\begin{array}{l}
i_{s \alpha} \\
i_{s \beta}
\end{array}\right]+\frac{d}{d t}\left[\begin{array}{l}
\psi_{s \alpha} \\
\psi_{s \beta}
\end{array}\right] .
$$

The flux linkages can be described by the stator currentrelated term and the rotor permanent magnet-related term as follows.

$$
\left[\begin{array}{l}
\psi_{s \alpha} \\
\psi_{s \beta}
\end{array}\right]=\boldsymbol{L}_{s}\left[\begin{array}{c}
i_{s \alpha} \\
i_{s \beta}
\end{array}\right]+\psi_{f}\left[\begin{array}{c}
\cos \theta_{e} \\
\sin \theta_{e}
\end{array}\right] .
$$

The inductance matrix $L_{s}$ is

$$
\begin{gathered}
\boldsymbol{L}_{s}=\left[\begin{array}{cc}
L_{\mathrm{sum}}+L_{\mathrm{dif}} \cos 2 \theta_{e} & -L_{\mathrm{dif}} \sin 2 \theta_{e} \\
L_{\mathrm{dif}} \sin 2 \theta_{e} & L_{\mathrm{sum}}+L_{\mathrm{dif}} \cos 2 \theta_{e}
\end{array}\right] \\
L_{\mathrm{sum}}=\frac{L_{q}+L_{d}}{2}, L_{\mathrm{dif}}=\frac{L_{q}-L_{d}}{2} .
\end{gathered}
$$

When the frequency of voltage injection signal is much higher than the fundamental frequency, the voltage drop of the stator resistance can be ignored. The permanent magnet-related terms and speed-related terms can be neglected as well because they are low frequency terms and hence their influence will be eliminated by the bandpass filters.

The high-frequency impedance model can be simplified as (7)

$$
\left[\begin{array}{l}
u_{s \alpha h}^{*} \\
u_{s \beta h}^{*}
\end{array}\right]=\boldsymbol{L}_{s} \frac{d}{d t}\left[\begin{array}{l}
i_{s \alpha h}^{*} \\
i_{s \beta h}^{*}
\end{array}\right]
$$

where $\left[u_{s \alpha h}^{*} u_{s \beta h}^{*}\right]^{\mathrm{T}}$ and $\left[i_{s \alpha h}^{*} i_{s \beta h}^{*}\right]^{\mathrm{T}}$ are the injected highfrequency voltage and the corresponding current in the stationary reference frame, respectively. The injected highfrequency voltage signal can be described as (8), where $V_{\text {in }}$ and $\omega_{\text {in }}$ are the magnitude and frequency of the injected rotating voltage, respectively.

$$
\left[\begin{array}{l}
u_{\text {sain }}^{*} \\
u_{s \beta i n}^{*}
\end{array}\right]=V_{\text {in }}\left[\begin{array}{c}
\cos \omega_{\text {in }} t \\
\sin \omega_{\text {in }} t
\end{array}\right] \text {. }
$$

From (7) and (8), the induced high-frequency currents can be described as

$$
\left[\begin{array}{l}
i_{\text {sain }}^{*} \\
i_{s \beta i n}^{*}
\end{array}\right]=\frac{V_{\mathrm{in}}}{\omega_{\mathrm{in}} L_{d} L_{q}}\left[\begin{array}{c}
L_{\mathrm{sum}} \sin \omega_{\mathrm{in}} t+L_{\mathrm{dif}} \sin \left(2 \theta_{e}-\omega_{\mathrm{in}} t\right) \\
-L_{\mathrm{sum}} \cos \omega_{\mathrm{in}} t-L_{\mathrm{dif}} \cos \left(2 \theta_{e}-\omega_{\mathrm{in}} t\right)
\end{array}\right] .
$$

Because only the second current component of the highfrequency current contains rotor position information, the heterodyning demodulation process can be utilized to filter out the first current component to extract the rotor position information. As shown in Fig. 1, the induced high-frequency currents are respectively multiplied by the sine and cosine functions and subtracted. By deriving, the frequency of the first current component in the current difference is converted to $2 \omega_{\text {in }}$ while the frequency of the second current component is converted to 0 . Then with a simple derivation, the rotor position tracking error can be obtained by low pass filtering as follows.

$$
\varepsilon=\frac{V_{\mathrm{in}}}{\omega_{\mathrm{in}} L_{d} L_{q}} L_{\mathrm{dif}} \sin 2\left(\theta_{e}-\theta_{r}\right) \cdot \frac{\omega_{\mathrm{in}} L_{d} L_{q}}{V_{\mathrm{in}} L_{\mathrm{dif}}} \approx 2\left(\theta_{e}-\theta_{r}\right) .
$$

where $\theta_{e}$ and $\theta_{r}$ represent the actual rotor position and the estimated rotor position, respectively.

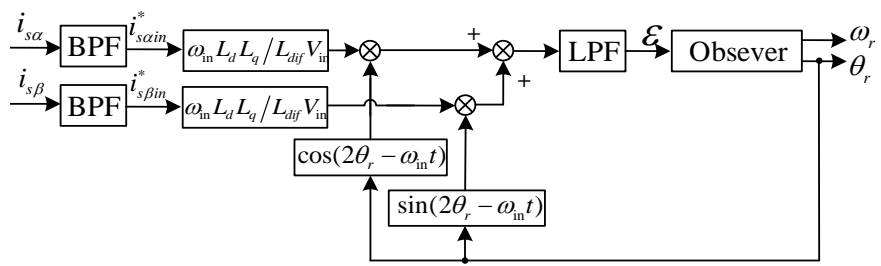

Fig. 1. Block diagram of the heterodyning demodulation process.

\section{High-SpeEd Modeling ANd CONTROL}

When the motor runs at low speed, the signal-to-noise ratio of useful signals is very low and high-frequency signal injection is an effective method to extract the location information. However, this method is not suitable for high-speed sensorless vector control of IPMSM. Hence, a new control strategy for finite position set-PLL is proposed for the high-speed position sensorless control.

A high-performance vector control scheme for IPMSMs can be implemented in the synchronously oriented rotating frame, which contains the rotor position information.

Substituting (2) into (1) yields

$$
\left\{\begin{array}{l}
u_{s d}=R_{s} i_{s d}+L_{d} \frac{d}{d t} i_{s d}-\omega_{e} L_{q} i_{s q} \\
u_{s q}=\omega_{e} \psi_{f}+R_{s} i_{s q}+L_{q} \frac{d}{d t} i_{s q}+\omega_{e} L_{d} i_{s d}
\end{array} .\right.
$$

The mechanical equation of motion of the motor can be expressed as

$$
\left\{\begin{array}{l}
\frac{d \omega_{m}}{d t}=\frac{1}{J}\left(T_{e}-T_{L}-v \omega_{m}\right) \\
T_{e}=\frac{3}{2} p_{n} i_{s q}\left[i_{s d}\left(L_{d}-L_{q}\right)+\psi_{f}\right]
\end{array}\right.
$$

where $\omega_{m}$ is the mechanical angular speed of the rotor, $p_{n}$ the number of pole pairs, $v$ viscous friction coefficient, and $J$ the overall rotor inertia. $T_{e}$ and $T_{L}$ are the electromagnetic torque and the mechanical torque, respectively. 


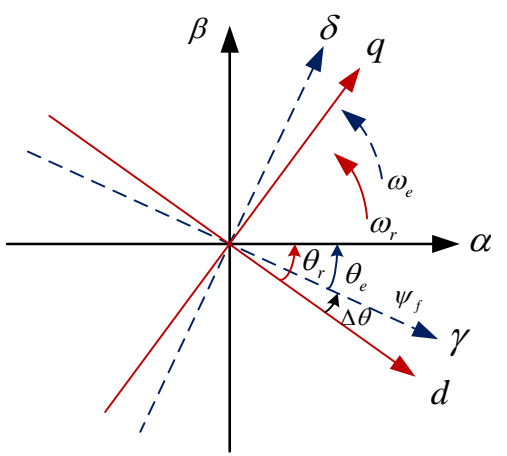

Fig. 2. Space vector diagram of a permanent-magnet flux-oriented reference frame.

Fig. 2 shows the space vector diagram of the expected permanent flux linkage in the $\psi_{f}$ oriented $\gamma-\delta$ reference frame and the sensorless estimated $d-q$ reference frame. The two reference frames are assigned to rotate at the actual and estimated electrical angular velocities of $\omega_{e}$ and $\omega_{r}$, respectively. From (11), it can be seen that the ideal $d-q$ model in the synchronously rotating reference frame cannot be utilized for sensorless control for lacking rotor position information. As shown, $\theta_{e}$ and $\theta_{r}$ are the actual and estimated position angles, respectively. And the estimated rotating $d-q$ frame lags by $\Delta \theta$ from the $\gamma-\delta$ reference frame. The mathematical model in the estimated rotating $d-q$ reference frame is derived as follows.

$$
\left\{\begin{array}{l}
u_{s d}=R_{s} i_{s d}+L_{d} \frac{d}{d t} i_{s d}-\omega_{e} L_{q} i_{s q}+\varepsilon_{s d} \\
u_{s q}=R_{s} i_{s q}+L_{q} \frac{d}{d t} i_{s q}+\omega_{e} L_{d} i_{s d}+\varepsilon_{s q}
\end{array}\right.
$$

where $\varepsilon_{s d}$ and $\varepsilon_{s q}$ are the back-EMF components, which contain many trigonometric terms function of the error between real and estimated rotor position. In order to simplify the expression of the back-EMF terms, the effects due to saliency are ignored [10], and the simplified expression is described as

$$
\left[\begin{array}{c}
E_{s d} \\
E_{s q}
\end{array}\right]=E_{s}\left[\begin{array}{c}
-\sin (\Delta \theta) \\
\cos (\Delta \theta)
\end{array}\right]=\omega_{e}\left[\left(L_{d}-L_{q}\right) i_{s d}+\psi_{f}\right]\left[\begin{array}{c}
-\sin (\Delta \theta) \\
\cos (\Delta \theta)
\end{array}\right] .
$$

When the $d$-axis is aligned with the $\gamma$-axis, the $d$-axis back EMF $E_{s d}$ can be assumed as zero. For a small error between $\theta_{e}$ and $\theta_{r}$, it can be considered that $E_{s d}=\Delta \theta$. Accordingly, $E_{s d}$ can be used to indicate whether or not the $d$-axis is aligned with the permanent magnet flux linkage $\psi_{f}$. Hence, the backward Euler method with sampling time $T_{s}$ is utilized to discretize the mathematic model of the IPMSM as (15).

$$
\left\{\begin{aligned}
u_{s d}(k)= & E_{s d}(k)+R_{s} i_{s d}(k)+L_{d} \frac{i_{s d}(k)-i_{s d}(k-1)}{T_{s}} \\
& -\omega_{e}(k) L_{q} i_{s q}(k) \\
u_{s q}(k)= & E_{s q}(k)+R_{s} i_{s q}(k)+L_{q} \frac{i_{s q}(k)-i_{s q}(k-1)}{T_{s}} \\
& +\omega_{e}(k) L_{d} i_{s d}(k)
\end{aligned}\right.
$$

where $k$ is a discrete sample time index. From (15), $E_{s d}$ and $E_{s q}$ can be obtained as

$$
\left\{\begin{array}{rl}
E_{s d}(k)= & -R_{s} i_{s d}(k)-L_{d} \frac{i_{s d}(k)-i_{s d}(k-1)}{T_{s}}+u_{s d}(k) \\
& +\omega_{e}(k) L_{q} i_{s q}(k) \\
E_{s q}(k)= & -R_{s} i_{s q}(k)-L_{q} \frac{i_{s q}(k)-i_{s q}(k-1)}{T_{s}}+u_{s q}(k) \\
& -\omega_{e}(k) L_{d} i_{s d}(k)
\end{array} .\right.
$$

Accordingly, the estimated rotor position $\theta_{r}$ is used for the transformation of the voltages and currents signals from $\alpha-\beta$ frame to $d-q$ frame. Then the transformed $d-q$ axis voltages and currents are substituted into (16) together with the machine parameters to calculate the $d$-axis back EMF $E_{s d}$ synchronous with the estimated rotor position. The closer $E_{s d}$ is to zero, the more accurate the estimated rotor position.

In the conventional PLL as illustrated in Fig. 3, the estimated back EMF $E_{s d}$ is fed back and subtracted from the reference value $E_{s d}^{*}=0$ to obtain the estimated error $\Delta E_{s d}=E_{s d}-E_{s d}^{*}$, which is sent to the PI regulator to derive the compensation term $\Delta \omega$. Meanwhile, the $q$-axis component $E_{s q}$ calculated from (16) is used to derive the normalized feed-forward term by using

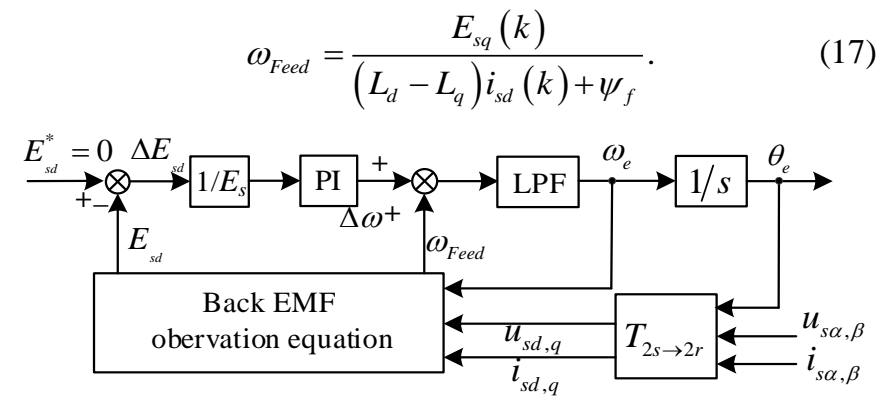

Fig. 3. Block diagram of the conventional PLL based on sensorless observation.

However, a fixed-gain PI controller may not guarantee the required performance due to continuing changes of machine parameters, operating conditions and nonlinearities in the inverter. Fortunately, the proposed PLL method for sensorless control strategy can cope with such problems. Fig. 4 illustrates a block diagram for the proposed PLL. The idea of this PLL stems from the FCS-MPC. During the discrete control period, the FCS-MPC solves the open-loop optimization problem in the finite time domain online based on the current output measurement value of the controlled object or the observed state variables, while limits the control input set to a finite number of switch combinations of the inverter. The complex optimization problem corresponding to the value function is transformed into an integer programming problem, and the switching state that minimizes a predefined cost function will be selected and applied to the controlled object in the next sampling interval. 


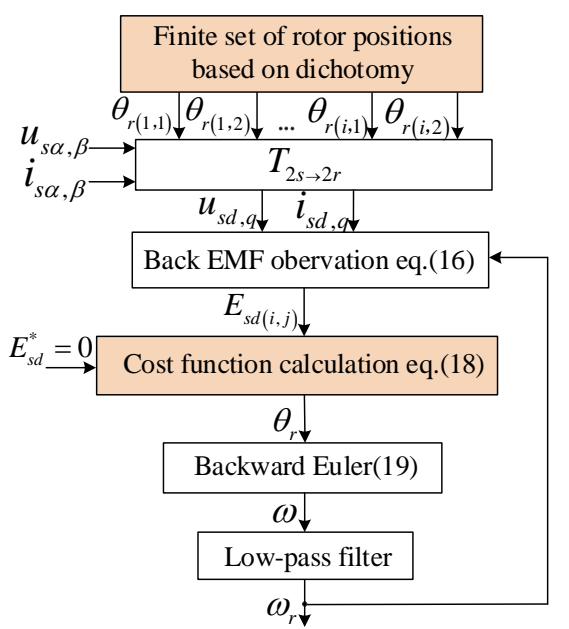

Fig. 4. Block diagram of the proposed PLL for sensorless control of IPMSM.

In order to obtain the optimal rotor position from a finite number of rotor positions, a cost function is formulated to evaluate the fitness of each position angle as (18). Furthermore, considering that the rotor position angle varies continuously from 0 to $2 \pi$ while the inverter has discrete switching states, an iterative search strategy based on dichotomy is proposed to discretize rotor position angles to obtain a finite number of positions. The flowchart of the proposed search algorithm is illustrated in Fig. 5.

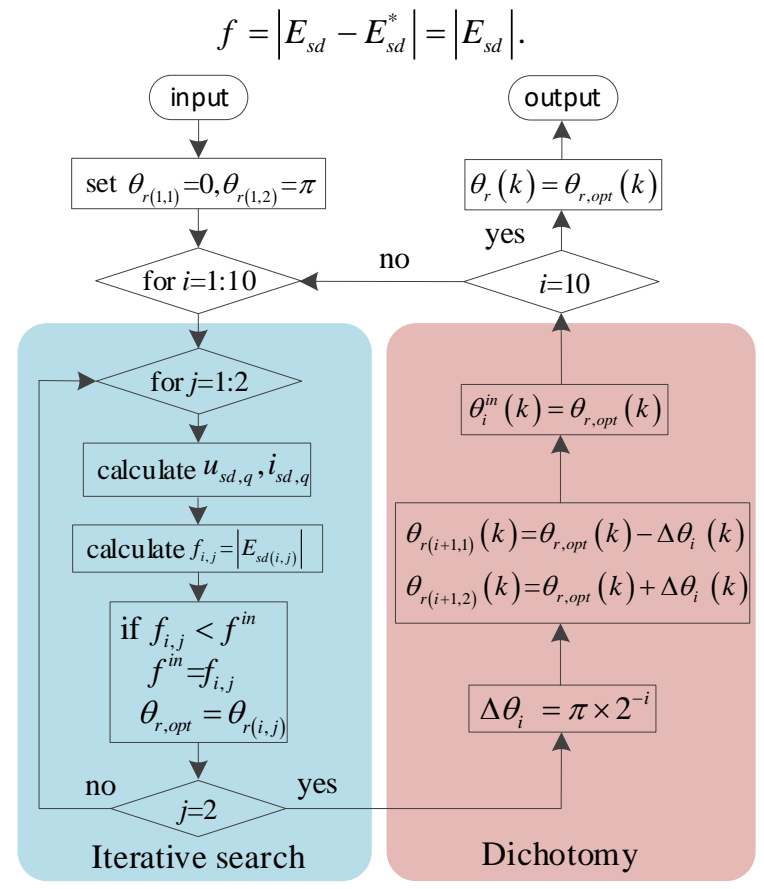

Fig. 5. Flowchart of the proposed iterative search algorithm.

The algorithm starts by reading the actual values of the currents $i_{s d, q}(k)$ and voltages $u_{s d, q}(k)$. Then the initial rotor angle $\theta_{r}^{i n}(k)=0$ and initial cost function value $f^{i n}=+\infty$ are defined. In order to obtain the optimal rotor position angle, dichotomy is used for ten iterations to approximate the optimal angle as shown in Fig. 6, which includes six main steps as follows.
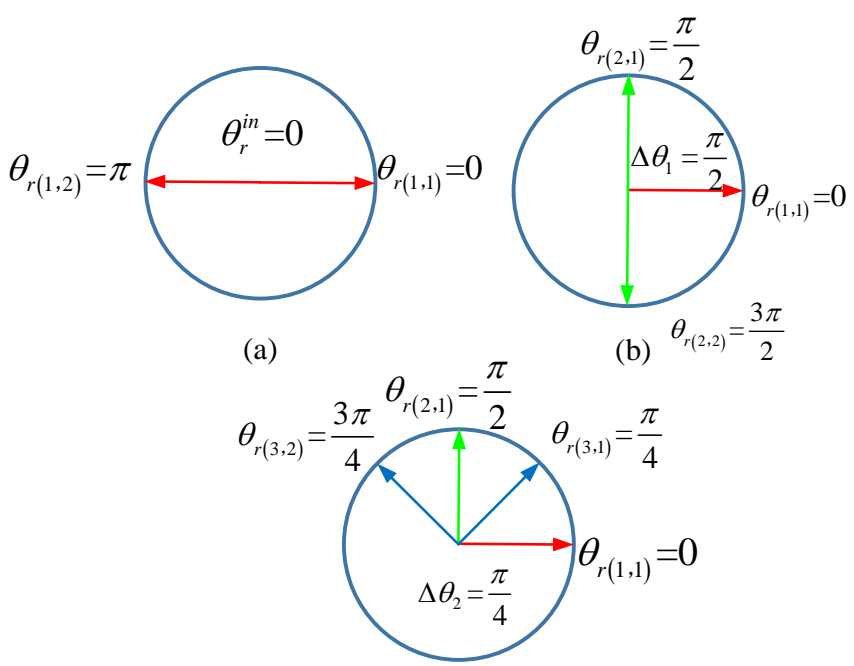

(c)

Fig. 6. Graphic representation of the first three iterations of the proposed iterative search strategy.

Step 1: Sample current and voltage data and initialize the position angle and the cost function.

Step 2: Divide the angle from 0 to $2 \pi$ rad into two equal parts, thus two discrete angles for the rotor position will be generated: $\theta_{r(1,1)}=0, \theta_{r(1,2)}=\pi$ rad. [see Fig. 6(a)].

Step 3: Use these two position angles to calculate back EMF $E_{s d(i, j)}$. The rotor position that can yield a smaller absolute value of the back EMF is chosen as a relative optimal rotor position angle. Assume the relative optimal rotor position angle is $\theta_{r(1,1)}$.

Step 4: Calculate $\Delta \theta_{l}$ to obtain new discrete angles $\theta_{r(2,1)}=\frac{1}{2} \pi$, $\theta_{r(2,2)}=\frac{3}{2} \pi$, which are used for next iteration to obtain a relative optimal position angle with higher precision improved by a factor of 2. [see Fig. 6(b)].

Step 5: Use the three position angles $\theta_{r(2,1)}, \theta_{r(2,2)}$ and $\theta_{r(1,1)}$ to calculate back EMF $E_{s d(i, j)}$. The rotor position that yields the minimal back EMF is chosen as the new relative optimal rotor position angle.

Step 6: Complete ten iterations to obtain the final optimal angle as the output.

Accordingly, the proposed iterative search algorithm converges to the optimal rotor position angle with the increase of iterations. The obtained optimal rotor position angle after ten iterations can hold an accuracy of $\pi \times 2^{-10}$. Hence, the estimated rotor angle obtained by the proposed PLL method has sufficiently high precision. It needs to complete the calculation of fitness function values corresponding to 20 discrete position angles. Compared with the proposed search method, the search method proposed in [15] and [36] needs to calculate the fitness function corresponding to 48 discrete position angles to hold the same position accuracy. Therefore, the proposed search strategy requires a smaller computational burden.

After obtaining the optimal rotor position angle, the estimated rotor speed $\omega$ can be calculated with the backward Euler method as

$$
\omega(k)=\frac{\theta_{r}(k)-\theta_{r}(k-1)}{T_{s}} .
$$


A low pass filter (LPF) is used to filter out high-frequency signals caused by angle switching and obtain the rotor speed signal $\omega_{r}$ as illustrated in Fig. 4.

Compared to the conventional PLL based on sensorless observation, the main advantage of the proposed PLL method is that there is no need to tune the parameters of the PI controller. It directly searches for the rotor position angle; therefore, the algorithm can be extended to other types of machines for angle determination. However, the problem with this approach is that all calculations need to be completed in one cycle. Consequently, it is necessary to determine that the sampling period is greater than the time required to execute the algorithm and control. Since the rotor position angle of the algorithm output is selected from the finite set positions instead of the actual position angle, the estimated angle contains ripples, and the magnitude of the ripples depends on the accuracy of the algorithm. As shown in Fig. 5, if the number of algorithm iterations increases to 12 , the accuracy error of the proposed PLL method can be reduced to be $\pi \times 2^{-12} \mathrm{rad}$, much smaller than the error of the algorithm with 10 iterations.

Consequently, the ripples in the estimated rotor position angle will be remarkably reduced. Meanwhile, the speed of algorithm calculation is more demanding.

Furthermore, the mechanical variable is assumed to be constant within one mechanical cycle. Therefore, the number of the algorithm iterations that satisfies certain accuracy requirements will be remarkably reduced when the search is executed near the previous relative optimal position angle.

\section{iV. Hybrid Control Strategy in Transition Region}

When performing high and low-speed control, it is necessary to switch between the two algorithms, and an appropriate switching strategy is necessary. If the switching method is not appropriate, it will cause a current surge at the moment of switching. In a more serious situation, the switching will fail and the motor will lose synchronization. In this paper, the switching process is divided into two phases; the first phase is the transition of angle and speed, and the second phase is the transition of injection voltage.

First, the position signals obtained by the two speed control methods are weighted as follows.

$$
\theta_{r}=\lambda \theta_{r 1}+(1-\lambda) \theta_{r 2}
$$

where $\theta_{r 1}$ and $\theta_{r 2}$ represent the estimated rotor position angles by the two speed control methods, respectively. $\theta_{r}$ is the mixed angle signal and $\lambda$ is the weighting factor, which is defined by the upper and lower limits of the rotor speed in the transition region as (21)

$$
\lambda=\left\{\begin{array}{cl}
1 & \omega_{e} \leq \omega_{L} \\
\frac{\omega_{H}-\omega_{e}}{\omega_{H}-\omega_{L}} & \omega_{L}<\omega_{e}<\omega_{H} \\
0 & \omega_{e} \geq \omega_{H}
\end{array}\right.
$$

where $\omega_{L}$ and $\omega_{H}$ are the upper and lower limits of the rotor speed in the transition region, respectively.

As expressed in (20), when the rotor speed is greater than $\omega_{L}$ and lower than $\omega_{H}$, the hybrid control strategy is carried out during the transition region. A mixed rotor position angle signal is obtained by the weighting function.

When the motor accelerates up to $\omega_{H}$, the first phase ends and the second phase begins, in which the rotor angle is obtained only by the proposed PLL method. However, the injection voltage still exists, and its sudden change in the injection voltage inevitably causes motor jitter, which affects the smoothness of the switching process. In order to avoid sudden changes in the injection voltage, a speed-based ramp function to gradually reduce the injection voltage to zero is designed as follows.

$$
V=\frac{\omega_{V 0}-\omega_{e}}{\omega_{V 0}-\omega_{H}} V_{\text {in }}
$$

where $\omega_{V 0}$ is the rotor speed when the injection voltage is zero. Since the action time of the voltage ramp is the end of the transition region, the rotor position and speed are obtained by the proposed PLL method at this time. Therefore, the identification accuracy at low speed is not affected.

\section{EXPERIMENTAL RESULTS}

In order to validate the system performance with the proposed PLL method, comparisons between the proposed PLL scheme and the conventional PLL method have been carried out through several experiments. The experimental setup is shown in Fig. 7. The test bench consists of an IPMSM (REMY HVH250 motor used for EVs), a torque sensor, and a magnetic powder brake.

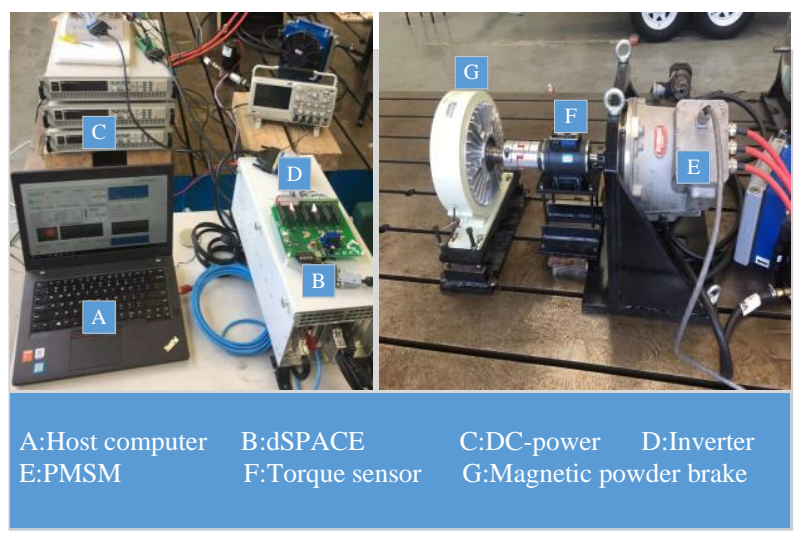

Fig. 7. Experimental setup used to verify the purposed PLL method.

The proposed control scheme is implemented in a dSPACE 1007 test bench. The experimental measurements are exported from the dSPACE platform to MATLAB and plotted. The IPMSM and system parameters are listed in Table I.

Since conventional heterodyning demodulation process is adapted for the zero speed and low-speed ranges, the analysis focuses on the proposed PLL control in the high-speed range and hybrid control strategy in the transition region. In this paper, the mechanical speed operation range is selected from 100$1500 \mathrm{rpm}$ to present the performance of the proposed observer in medium and high speeds. Due to the large amount of calculations required, the execution time of the sensorless control with the proposed PLL method is longer than that with conventional PLL. 
IPMSM AND SYSTEM PARAMETERS

\begin{tabular}{lcl}
\hline \hline Parameter & Symbol & Value \\
\hline No. of pole pairs & $P$ & 5 \\
Stator resistance & $R_{s}$ & $0.18 \Omega$ \\
$d$-axis inductance & $L_{d}$ & $0.174 \mathrm{mH}$ \\
$q$-axis inductance & $L_{q}$ & $0.29 \mathrm{mH}$ \\
Permanent-magnet flux linkage & $\psi_{f}$ & $0.0711 \mathrm{~Wb}$ \\
Inertia & $J$ & $0.067 \mathrm{kgm}^{2}$ \\
Rated speed & $N$ & $2000 \mathrm{rpm}$ \\
Rated power & $P_{N}$ & $60 \mathrm{~kW}$ \\
\hline \hline
\end{tabular}

\section{A. Comparisons under steady state condition}

Fig. 8 shows the steady-state performance of the proposed PLL method and the conventional PLL method. The reference mechanical speed $\omega_{m}$ of the rotor is set to $1000 \mathrm{rpm}$. From top to bottom, the plotted signals are estimated speed $\omega_{r}$, error $\Delta \omega=\omega_{e}-\omega_{r}$ between the actual and estimated rotor speeds; error $\Delta \theta=\theta_{e}-\theta_{r}$ between the actual and estimated rotor position angles. As shown, the traditional PLL method produces about $2.4 \mathrm{rpm}$ speed error and $0.022 \mathrm{rad}$ position angle error under steady state condition, while the speed and position angle error with the proposed PLL method are $2.8 \mathrm{rpm}$ and $0.028 \mathrm{rad}$. Therefore, the proposed novel method produces slightly larger ripples in the estimated position and speed than conventional PLL method. The slowness of response resulting from the particular tuning of the standard PLL can be the reason for the reduced ripple in the position and speed estimations when compared with the proposed PLL. However, such ripples are still acceptable and the ripples can be further attenuated by increasing the number of algorithm iterations as analyzed in section III.
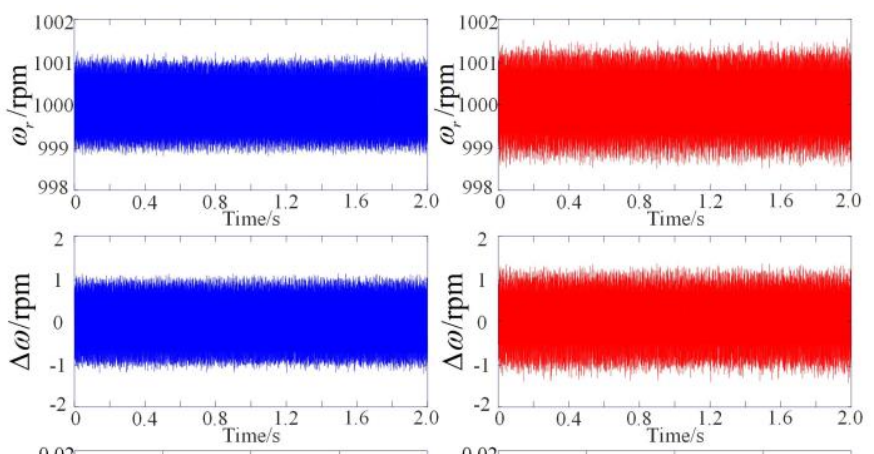

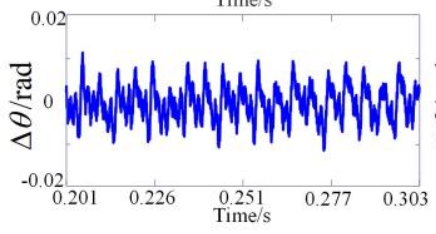

(a)
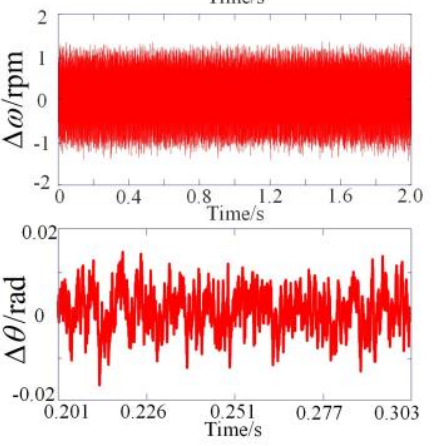

(b)
Fig. 8. Experimental performance at steady state: (a) conventional PLL, and (b) proposed PLL.

\section{B. Comparisons under reference speed step change condition}

In order to compare the dynamic response of the two methods under step changes in the rotor speed, the dynamic response of them is shown in Fig. 9. As can be seen, two step changes in the reference mechanical speeds of the rotor from 1000-1500 rpm and $1500-1000 \mathrm{rpm}$ have been applied to the system at time instant $t_{1}=0.7 \mathrm{~s}$ and $t_{2}=1.3 \mathrm{~s}$, respectively. The maximum speed error $\Delta \omega$ with the conventional PLL is $30 \mathrm{rpm}$, while that with the proposed PLL is $18 \mathrm{rpm}$. With the step changes at $t_{1}$ and $t_{2}$, it respectively takes $0.24 \mathrm{~s}$ and $0.2 \mathrm{~s}$ to bring the speed error $\Delta \omega$ closer to zero with the traditional PLL method, while the proposed novel method takes $0.11 \mathrm{~s}$ and $0.09 \mathrm{~s}$ to make the speed error closer to zero. Additionally, the rotor position angle error $\Delta \theta$ using the traditional PLL method maintains a certain error of $-0.16 \mathrm{rad}$, while that of the proposed PLL method converges to zero with little time. Consequently, the transient performance of the proposed PLL method is better than that of the conventional PLL. It can be further observed that the error is larger than the error analyzed in Section III, which is the result of non-model dynamics of the machine, inverter nonlinearities, and harmonics in the back EMF. Despite of the errors caused by the above reasons, the accuracy of the algorithm is still acceptable.
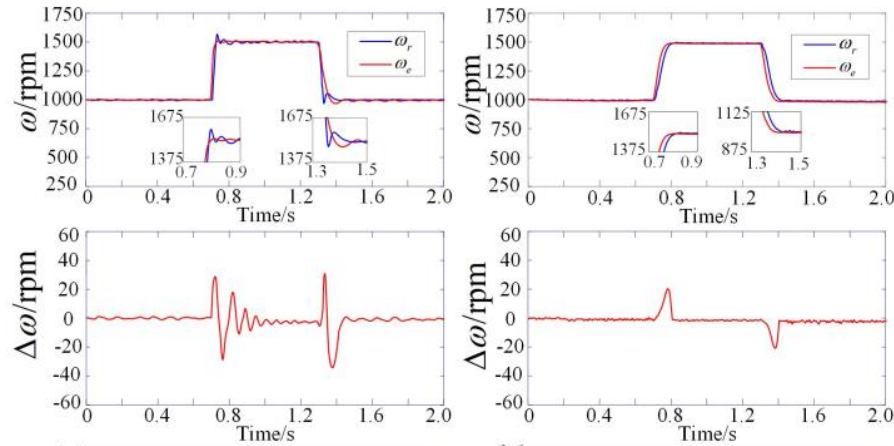

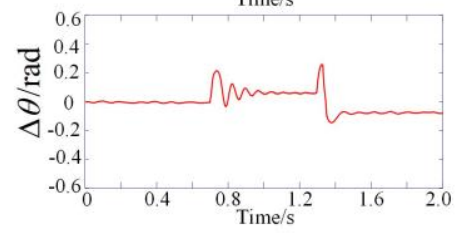

(a)

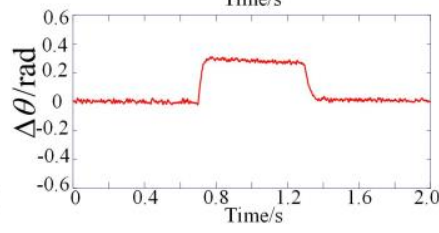

(b)
Fig.9. Experimental performance under reference speed step changes condition: (a) conventional PLL, and (b) proposed PLL.

\section{Comparisons under load torque step change condition}

In order to compare the dynamic response under step changes in the load torque $T_{L}$, the dynamic response of the two methods are shown in Fig. 10. At the time instant $t_{1}=0.7 \mathrm{~s}$ and $t_{2}=1.3 \mathrm{~s}$, two step changes in the load torque from $20-40 \mathrm{Nm}$ and $40-20$ $\mathrm{Nm}$ have been applied to the system. As shown, compared with the traditional PLL method, the proposed PLL method maintains a better dynamic performance. The traditional PLL method takes about $0.2 \mathrm{~s}$ and $0.18 \mathrm{~s}$ to minimize the speed error when the step changes in the load torque are applied to the system. The proposed method takes $0.1 \mathrm{~s}$ and $0.9 \mathrm{~s}$ to achieve the speed error close to zero. Meanwhile, the traditional PLL method produces an error of -0.21 radian in position angle, while the steady state position angle error of the novel method is about -0.05 radian. Consequently, the performance of the proposed PLL method is much better than that of the conventional PLL method under load torque step change condition. 

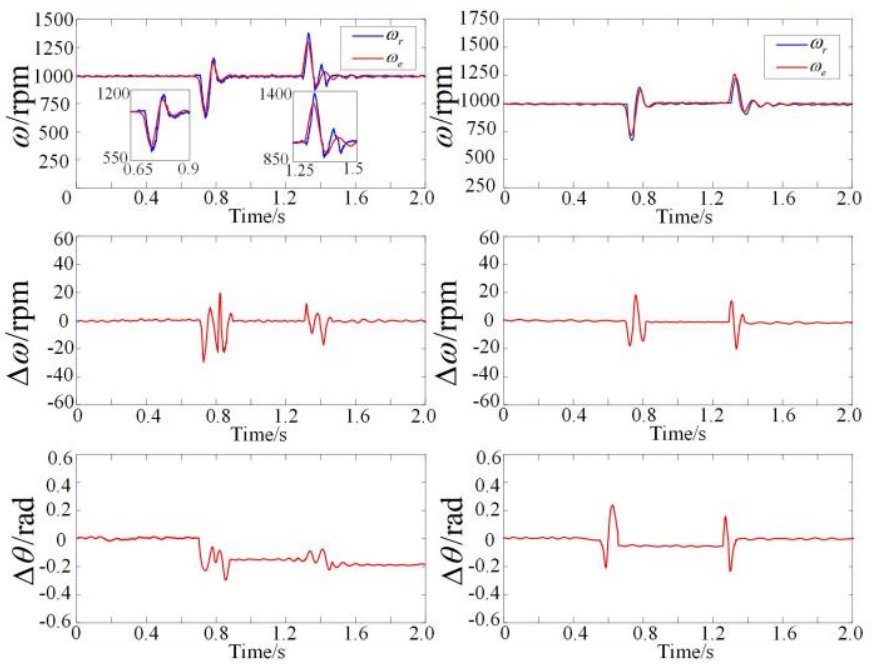

(a)

(b)

Fig. 10. Experimental performance under load torque step changes condition: (a) conventional PLL, and (b) proposed PLL.

\section{Robustness analysis}

The robust analyzes of the proposed PLL method and the conventional one are investigated. The experimental performance for $\pm 50 \%$ step changes in the stator resistance and $d-q$ axis inductances is presented in the Figs. 11-13, respectively. In the test, the machine runs at $1000 \mathrm{rpm}$ and noload in sensorless mode operation. As shown in Fig. 11, the step changes in stator resistance produce smaller errors in both speed estimation and position estimation with the proposed FCS-PLL method compared with that in the case of the conventional PLL method. According to Figs. 12 and 13, in the sensitivity test of both methods to inductance parameter changes, the proposed method shows better performance with less oscillation in both speed estimation and position estimation, while the drive system loses stability in the case of the conventional PLL method for the same level of inductance changes.
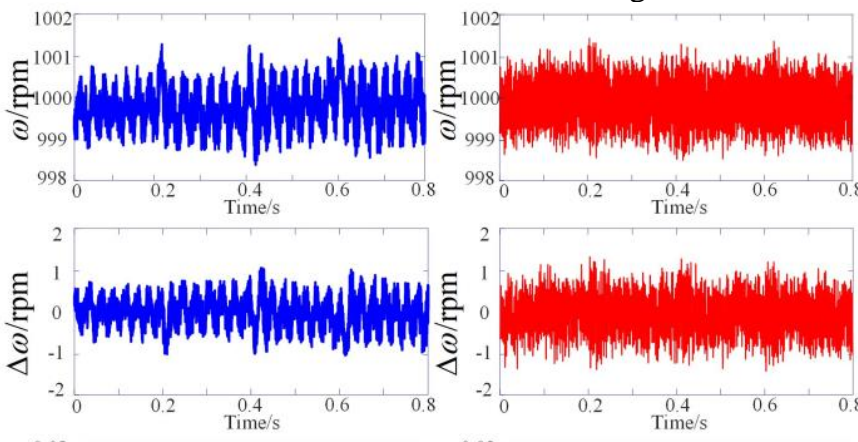

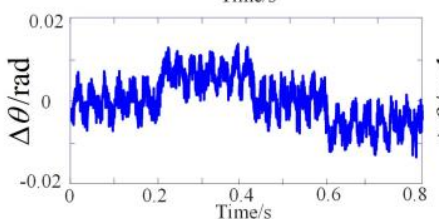

(a)

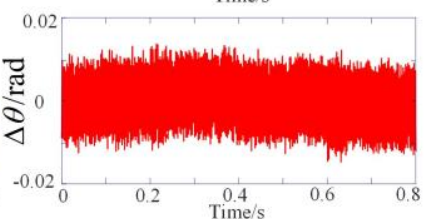

(b)
Fig. 11. Experimental performance under stator resistance change operation: (a) conventional PLL, and (b) proposed PLL.
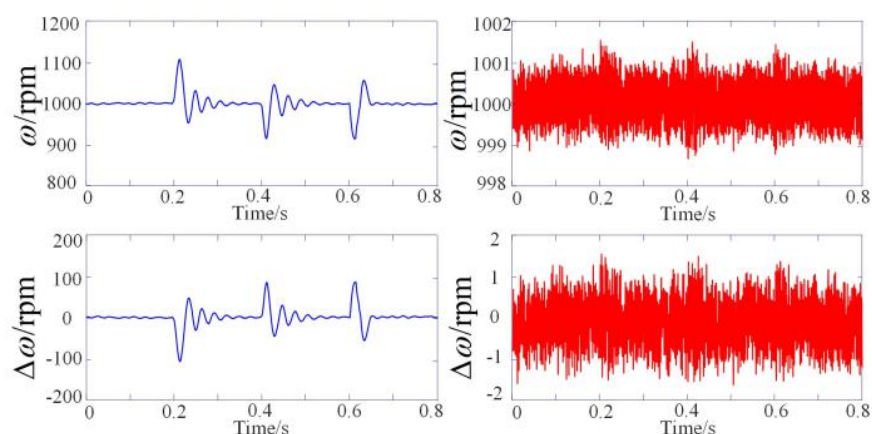

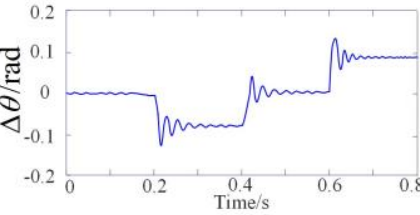

(a)

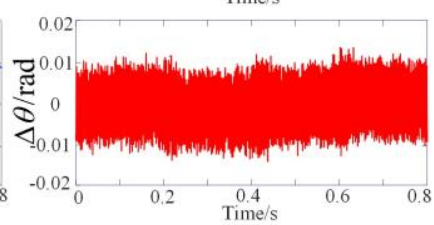

(b)
Fig. 12. Experimental performance under $d$-axis inductance change operation: (a) conventional PLL, and (b) proposed PLL.

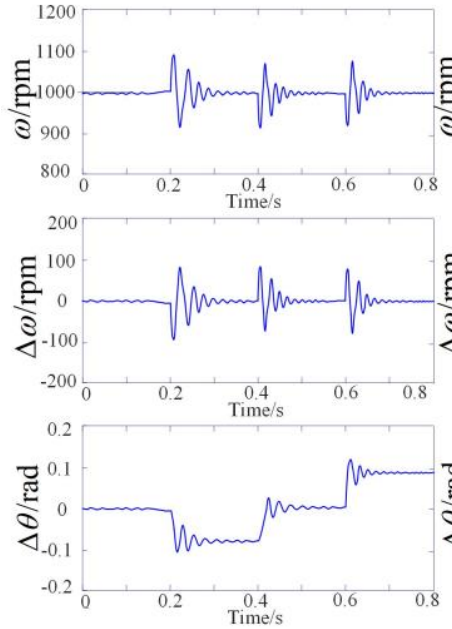

(a)
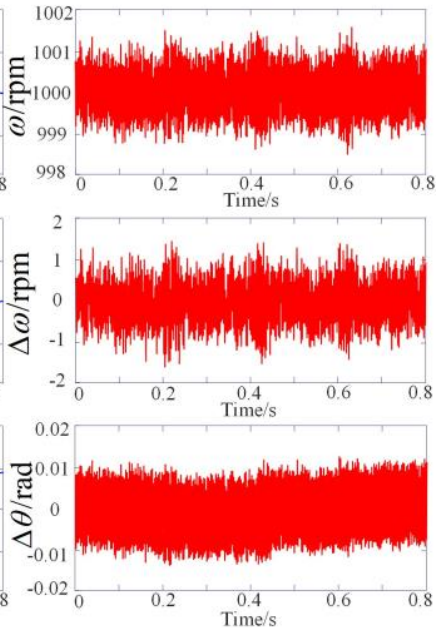

(b)

Fig. 13. Experimental performance under $q$-axis inductance change operation: (a) conventional PLL, and (b) proposed PLL.

\section{E. Experimental results under other operation}

Fig. 14 illustrates the experimental tests during zero and low speed region, field weakening region, speed reverse operation, and regeneration mode. In the zero and low speed region, highfrequency rotating voltage injection is applied to estimate the rotor position and speed. The frequency selection of the injected high-frequency voltage needs to consider some factors, including the maximum fundamental frequency, the current loop bandwidth, and the switching frequency of the power device. In engineering applications, the frequency of the high frequency voltage is selected as $5 \delta \leq \omega_{1} \leq \frac{\omega_{s w}}{10}$, where $\delta$ is the bandwidth of the current loop, $\omega_{s w}$ is the switching frequency of the power device. The amplitude of the high-frequency voltage is limited by the nonlinearity of the inverter and the accuracy of the current sensor. The amplitude of the high-frequency voltage is selected as $V_{\mathrm{in}} \geq \frac{I_{f} \omega_{1} L_{d} L_{q}}{10 L_{\mathrm{dif}}}$, where $I_{f}$ is the amplitude of the fundamental current. However, the amplitude of the injected high-frequency voltage should not be too large, because the power loss and noise will be higher with the increase of the amplitude. 
It can be observed that high-frequency rotating voltage injection can guarantee the stability of the sensorless control during zero and low speed region. Since the voltage injection method is applied at zero low speed, the low speed region of the speed reversal operation still adopts this method, and the experimental performance of the high and low speed switching region is given in Fig. 15. Under speed reverse operation, a step change in the reference speed from -100 to $100 \mathrm{rpm}$ has been applied to control system. Again, the rotating voltage injection yields a good performance with little position error.

Due to the DC-link voltage limitation, $i_{s d}=-3 \mathrm{~A}$ has to be imposed for flux-weakening. The proposed FCS-PLL still maintains good experimental performance in field weakening region. Under regeneration mode, the reference speed is set to $-1000 \mathrm{rpm}$, the proposed method yields consistent performance as the drive mode.
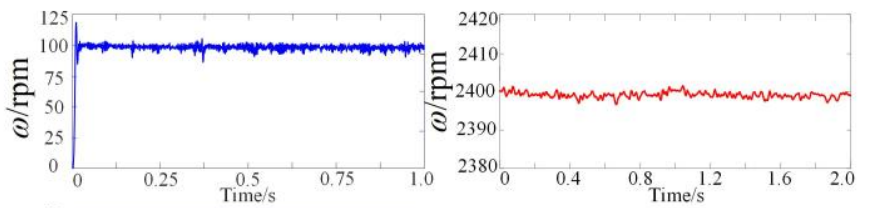

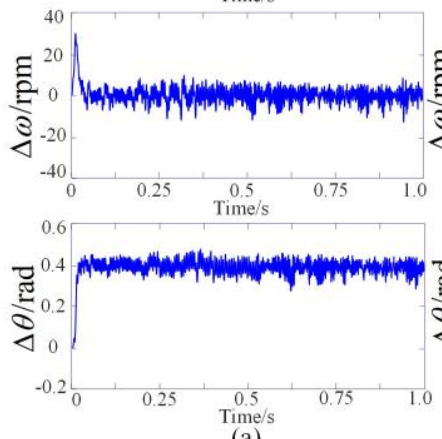

(a)
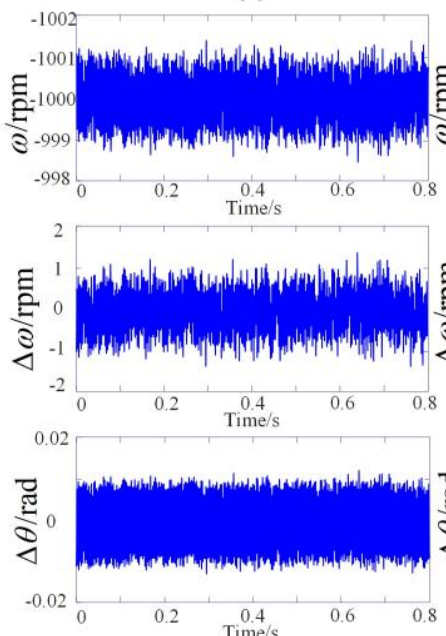

(c)

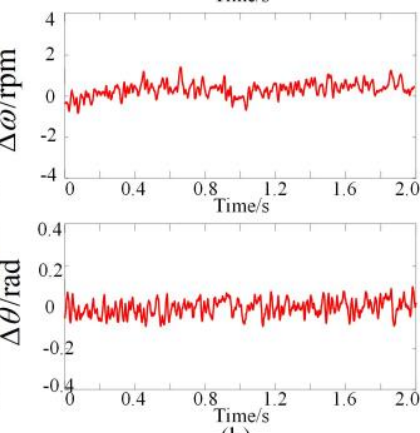

(b)
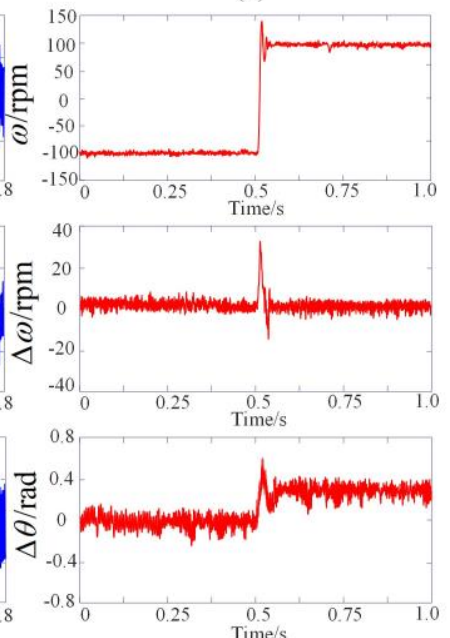

(d)
Fig. 14. Experimental performance under other operation condition: (a) zero and low speed region, (b) field weakening region, (c) regeneration mode, and (d) speed reverse operation.

Fig. 15 shows the dynamic response of the FOC scheme of the IPMSM using the hybrid control strategy when the motor is accelerated from standstill to rated speed under rated load conditions. From top to the bottom, the plotted signals are estimated speed $\omega_{r}$; error $\Delta \omega=\omega_{e}-\omega_{r}$ between the actual and estimated rotor speeds; and error $\Delta \theta=\theta_{e}-\theta_{r}$ between the actual and estimated rotor position angles. The upper limit of the rotor speed $\omega_{H}$ in the transition region is selected as $100 \mathrm{rpm}$, while the lower limit of the rotor speed $\omega_{L}$ is chosen as $200 \mathrm{rpm}$. As shown, the maximum error $\Delta \omega$ is about $30 \mathrm{rpm}$ and the error $\Delta \theta$ is no more than $0.5 \mathrm{rad}$ during the acceleration process, which indicates that the proposed hybrid control strategy can achieve smooth switching between the two speed sensorless control algorithms.

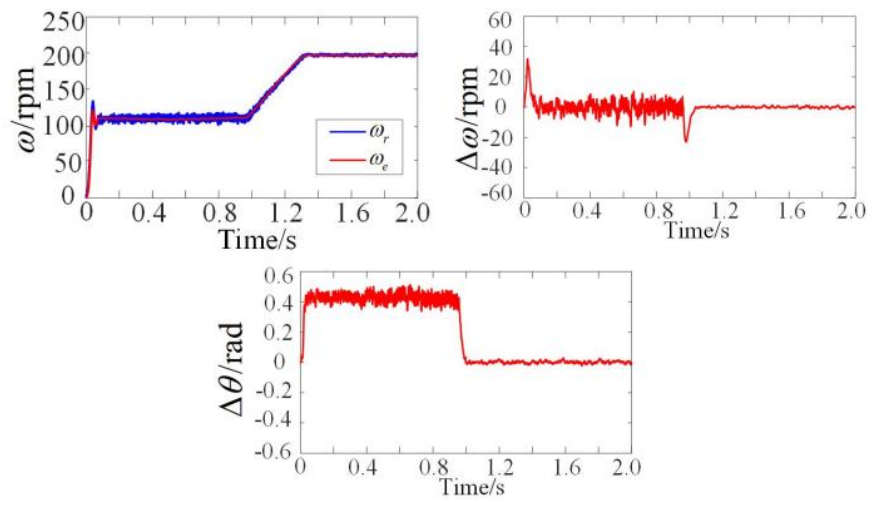

Fig. 15. Experimental performance in the transition region with the proposed PLL.

\section{CONCLUSION}

This paper presented an iterative search strategy based on dichotomy for the sensorless control of IPMSMs. The optimal rotor position angle was obtained by calculating and comparing the fitness function corresponding to the finite position set. The new method has the advantage of being able to maintain good performance under the steady-state condition and significantly reducing speed and angular oscillations as well as oscillation time under transient condition. Meanwhile, this method obtains rotor position information through direct calculation, avoiding the defect of delay caused by the inertia link of the traditional PLL. This helps improve the accuracy and dynamic performance of the control system. Furthermore, the performance of the motor with the hybrid control strategy is stable under transition condition. The motor speed and angular error are acceptable during the entire acceleration process. The sensitivity analysis has been provided to demonstrate the superiority of the proposed PLL. Detailed analysis to verify the proposed PLL method and the switching strategy was shown in the experiment results.

It should be noted that the accuracy of the position signal obtained by the iterative strategy is directly related to the number of iterations, the increase of which is bound to cause an increase in the computational load. Therefore, it is necessary to study the relationship between the accuracy of position signal and the calculation load. Additionally, compared with the convex optimization-based sensorless scheme in [24], the proposed FCS-PLL method is only suitable for medium and high speed sensorless control. However, the proposed searchbased strategy based on dichotomy can obtain high-precision position angles from finite positions set as the number of iterations increases, which takes less execution time. In future work, the convex optimization-based sensorless method will be investigated to achieve better full speed sensorless control 
based on the FCS-PLL method. Further, the proposed method will be researched based on the DSP and FPGA.

\section{REFERENCES}

[1] X. Zhu, Z. Shu, L. Quan, Z. Xiang, and X. Pan, "Design and multicondition comparison of two outer-rotor flux-switching permanent magnet motors for in-wheel traction applications," IEEE Trans. Ind. Electron., vol. 64, no. 8, pp. 6137-6148, Aug. 2017.

[2] X. Sun, C. Hu, Gang Lei, Y. Guo, and J. Zhu, "State feedback control for a PM hub motor based on grey wolf optimization algorithm," IEEE Trans. Power Electron., 2019, DOI: 10.1109/TPEL.2019.2923726.

[3] Q. Chen, W. Zhao, G. Liu, and Z. Lin, Extension of virtual-signalinjection-based MTPA control for five-phase IPMSM into fault tolerant operation. IEEE Trans. Ind. Electron., vol. 66, no. 2, pp. 944-955, Feb. 2019.

[4] Z. Shi, X. Sun, Y. Cai, Z. Yang, G. Lei, Y. Guo, and J. Zhu, "Torque analysis and dynamic performance improvement of a PMSM for EVs by skew angle optimization," IEEE Trans. Applied Supercond., vol. 29, no. 2, art. 0600305, Mar. 2019.

[5] X. Sun, L. Chen, H. Jiang, Z. Yang, J. Chen, and W. Zhang, "Highperformance control for a bearingless permanent magnet synchronous motor using neural network inverse scheme plus internal model controllers," IEEE Trans. Ind. Electron., vol. 63, no. 6, pp. 3479-3488, Jun. 2016

[6] Q. Chen, G. Xu, G. Liu, W. Zhao, Z. Lin, and L. Liu, Torque ripple reduction in five-phase interior permanent magnet motors by lowering interactional MMF. IEEE Trans. Ind. Electron., vol. 65, no. 11, pp. 85208531, Nov. 2018.

[7] X. Zhu, J. Huang, L. Quan, Z. Xiang, and B. Shi, "Comprehensive sensitivity analysis and multi-objective optimization research of permanent magnet flux-intensifying motors," IEEE Trans. Ind. Electron., vol. 66, no. 4, pp. 2613-2627, Apr. 2019.

[8] X. Sun, et. al, "MPTC for PMSMs of EVs with multi-motor driven system considering optimal energy allocation," IEEE Trans. Magn., vol. 55, no. 7, pp. 1-6, Jul 2019, Art. no.: 8104306.

[9] T. D. Batzel and K. Y. Lee, "Slotless permanent magnet synchronous motor operation without a high resolution rotor angle sensor," IEEE Trans. Energy Convers., vol. 15, no. 4, pp. 366-371, Dec. 2000.

[10] S. Morimoto, K. Kawamoto, M. Sanda, and Y. Takeda, "Sensorless control strategy for salient-pole PMSM based on extended EMF in rotating reference frame," IEEE Trans. Ind. Appl., vol. 38, no. 4, pp. 1054-1061, Jul./Aug. 2002.

[11] D. Liang, J. Li, R. Qu, and W. Kong, "Adaptive second-order slidingmode observer for PMSM sensorless control considering VSI nonlinearity," IEEE Trans. Ind. Electron, vol. 33, no. 10, pp. 8994-9004, Oct. 2018.

[12] D. Liang, J. Li, and R. Qu, "Sensorless control of permanent magnet synchronous machine based on second-order sliding-mode observer with online resistance estimation," IEEE Trans. Ind. Appl., vol. 53, no. 4, pp. 3672-3682, Jul./Aug. 2017.

[13] L. Zhao, J. Huang, H. Liu, B. Li, and W. Kong, "Second-order slidingmode observer with online parameter identification for sensorless induction motor drives," IEEE Trans. Ind. Electron., vol. 61, no. 10, pp. 5280-5289, Oct. 2014.

[14] T. Orlowska-Kowalska, M. Dybkowski, and K. Szabat, "Adaptive sliding mode neuro-fuzzy control of the two-mass induction motor drive without mechanical sensors," IEEE Trans. Ind. Electron., vol. 57, no. 2, pp. 553-564, Feb. 2010.

[15] Y. B. Zbede, S. M. Gadoue, and D. J. Atkinson, "Model predictive MRAS estimator for sensorless induction motor drives," IEEE Trans. Ind. Electron., vol. 63, no. 6, pp. 3511-3521, Sep. 2016.

[16] M. Comanescu and L. Xu, "Sliding-mode MRAS speed estimators for sensorless vector control of induction machine," IEEE Trans. Ind. Electron.,vol. 53, no. 1, pp. 146-153, Feb. 2006.

[17] A. Accetta, M. Cirrincione, M. Pucci, and G. Vitale, "Closed-loop MRAS speed observer for linear induction motor drives," IEEE Trans. Ind. Appl.,vol. 51, no. 3, pp. 2279-2290, May/Jun. 2015.

[18] M. Cirrincione, A. Accetta, M. Pucci, and G. Vitale, "MRAS speed observer for high-performance linear induction motor drives based on linear neural networks," IEEE Trans. Power Electron., vol. 28, no. 1, pp. 123-134, Jan. 2012.

[19] X. Sun, L. Chen, Z. Yang, and H. Zhu, "Speed-sensorless vector control of a bearingless induction motor with artificial neural network inverse speed observer," IEEE/ASME Trans. Mechatron., vol. 18, no. 4, pp. 1357-1366, Aug. 2013.

[20] F. Alonge, T. Cangemi, F. D'Ippolito, A. Fagiolini, and A. Sferlazza, "Convergence analysis of extended Kalman filter for sensorless control of induction motor," IEEE Trans. Ind. Electron., vol. 62, no. 4, pp. 23412352, Apr. 2015.

[21] R. Inan and M. Barut, "Bi input-extended Kalman filter-based speed sensorless control of an induction machine capable of working in the field-weakening region," Turkish J. Elect. Eng. Comput. Sci., vol. 22, no. 3, pp. 588-604, Apr. 2014

[22] M. Preindl and E. Schaltz, "Sensorless model predictive direct current control using novel second-order PLL observer for PMSM drive systems," IEEE Trans. Ind. Electron., vol. 58, no. 9, pp. 4087-4095, Sep. 2011.

[23] G. Wang, Z. Li, G. Zhang, Y. Yu, and D. Xu, "Quadrature PLL-based highorder sliding-mode observer for IPMSM sensorless control with online MTPA control strategy," IEEE Trans. Energy Convers., vol. 28, no. 1, pp. 214-224, Mar. 2013.

[24] L. Sun, S. Nalakath, A. Dorneles Callegaro, and A. Emadi, "Investigation of a practical convex optimization-based sensorless scheme for IPMSM drives," IEEE Trans. Power Electron. DOI: 10.1109/TPEL.2019.2906557, 2019

[25] X. Song, J. Fang, B. Han, and S. Zheng, "Adaptive compensation method for high-speed surface PMSM sensorless drives of EMF-based position estimation error," IEEE Trans. Power Electron., vol. 31, no. 2, pp. 14381449, Feb. 2016

[26] S. Bolognani, S. Calligaro, and R. Petrella, "Design issues and estimation errors analysis of back-EMF-based position and speed observer for SPM synchronous motors," IEEE J. Emerg. Sel. Topics Power Electron., vol. 2, no. 2, pp. 159-170, Jun. 2014.

[27] A. A. Ahmed, B. K. Koh, and Y. I. Lee, "A comparison of finite control set and continuous control set model predictive control schemes for speed control of induction motors," IEEE Trans. Ind. Informat., vol. 14, no. 4, pp. 1334-1346, Apr. 2018.

[28] M. Novak, U. M. Nyman, T. Dragicevic, and F. Blaabjerg, "Analytical design and performance validation of finite set MPC regulated power converters," IEEE Trans. Ind. Electron., vol. 66, no. 3, pp. 2004-2014, Mar. 2019.

[29] G. Prior and M. Krstic, "A control Lyapunov approach to finite control set model predictive control for permanent magnet synchronous motors," J. Dyn. Syst., Meas., Control, vol. 137, no. 1, Jan. 2015, Art. no. 011001.

[30] R. P. Aguilera and D. E. Quevedo, "On stability of finite control set MPC strategy for multicell converters," in Proc. IEEE Int. Conf. Ind. Technol., Mar. 2010, pp. 1277-1282.

[31] N. Panten, N. Hoffmann, and F. W. Fuchs, "Finite control set model predictive current control for grid-connected voltage-source converters with LCL filters: A study based on different state feedbacks," IEEE Trans. Power Electron., vol. 31, no. 7, pp. 5189-5200, Jul. 2016.

[32] H. T. Nguyen and J. Jung, "Finite control set model predictive control to guarantee stability and robustness for surface-mounted PM synchronous motors," IEEE Trans. Ind. Electron., vol. 65, no. 11, pp. 8510-8519, Nov. 2018.

[33] V. Yaramasu, M. Rivera, B. Wu, and J. Rodriguez, "Model predictivecurrent control of two-level four-leg inverters-Part I: Concept, algorithm, and simulation analysis," IEEE Trans. Power Electron., vol. 28, no. 7, pp. 3459-3468, Jul. 2013.

[34] S. Kouro, P. Cortes, R. Vargas, U. Ammann, and J. Rodriguez, "Model predictive control-A simple and powerful method to control power converters," IEEE Trans. Ind. Electron., vol. 56, no. 6, pp. 1826-1838, Jun. 2009.

[35] M. Habibullah, D. D. C. Lu, D. Xiao, and M. F. Rahman, "Finite-state predictive torque control of induction motor supplied from a three-level NPC voltage source inverter," IEEE Trans. Power Electron., vol. 32, no. 1, pp. 479-489, Jan. 2017.

[36] M. Abdelrahem, C. M. Hackl and R. Kennel, "Finite position set-phase locked loop for sensorless control of direct-driven permanent-magnet synchronous generators," IEEE Trans Power Electron., vol. 33, no. 4, pp. 3097-3105, Apr 2018.

[37] Z. Ma, S. Saeidi, and R. Kennel, "FPGA implementation of model predictive control with constant switching frequency for PMSM drives," IEEE Trans. Ind. Informat., vol. 10, no. 4, pp. 2055-2063, Nov. 2014.

[38] A. H. Almarhoon, Z. Q. Zhu, and P. Xu, "Improved rotor position estimation accuracy by rotating carrier signal onjection utilizing zerosequence carrier voltage for dual three-phase PMSM," IEEE Trans. Ind. Electron., vol. 64, no. 6, pp. 4454-4462, Jun. 2017. 
[39] S. Kim, J. Im, E. Song, and R. Kim, "A new rotor position estimation method of IPMSM using all-pass filter on high-frequency rotating voltage signal injection," IEEE Trans. Ind. Electron., vol. 63, no. 10, pp. 6499-6509, Oct. 2016.

[40] Q. Tang, A. Shen, X. Luo, and J. Xu, "PMSM sensorless control by injecting HF pulsating carrier signal into $\mathrm{ABC}$ frame," IEEE Trans. Power Electron., vol. 32, no. 5, pp. 3767-3776, May 2017.

[41] S. Jung and J. I. Ha, "Analog filtering method for sensorless AC machine control with carrier-frequency signal injection," IEEE Trans. Ind. Electron., vol. 62, no. 9, pp. 5348-5358, Sep. 2015.

[42] Z. Ma, J. Gao, and R. Kennel, "FPGA implementation of a hybrid sensorless control of SMPMSM in the whole speed range," IEEE Trans. Ind. Informat., vol. 9, no. 3, pp. 1253-1261, Aug. 2013.

[43] C. Silva, G. M. Asher, and M. Sumner, "Hybrid rotor position observer for wide speed-range sensorless PM motor drives including zero speed," IEEE Trans. Ind. Electron., vol. 53, no. 2, pp. 373-378, Apr. 2006.

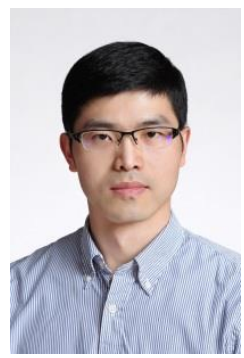

Xiaodong Sun (M'12-SM'18) received the B.Sc. degree in electrical engineering, and the M.Sc. and Ph.D. degrees in control engineering from Jiangsu University, Zhenjiang, China, in 2004, 2008, and 2011, respectively.

Since 2004, he has been with Jiangsu University, where he is currently a Professor with the Automotive Engineering Research Institute. From 2014 to 2015, he was a Visiting Professor with the School of Electrical, Mechanical, and Mechatronic Systems, University of Technology Sydney, Sydney, Australia. His current teaching and research interests include electrical machines and drives, drives and control for electric vehicles, and intelligent control. $\mathrm{He}$ is the author or coauthor of more than 90 refereed technical papers and one book, and he is the holder of 36 patents in his areas of interest.

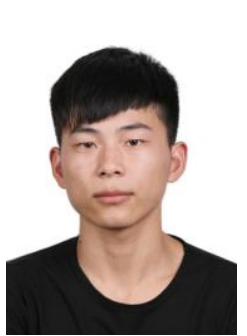

Junhao Cao was born in Huaian, Jiangsu, China, in 1994. He received the B.S. degree in vehicle engineering from Jiangsu University, Zhenjiang, China, in 2018, and he is currently working toward the M.E. degree in Jiangsu University, Zhenjiang, China.

His current research interests include control of electrical drive systems and advanced control strategy of electric machine.

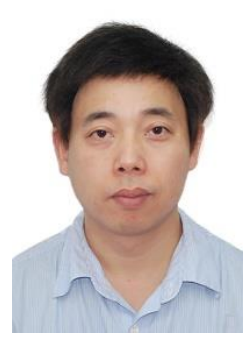

Gang Lei (M'14) received the B.S. degree in Mathematics from Huanggang Normal University, China, in 2003, the M.S. degree in Mathematics and Ph.D. degree in Electrical Engineering from Huazhong University of Science and Technology, China, in 2006 and 2009, respectively. He is currently a senior lecturer at the School of Electrical and Data Engineering, University of Technology Sydney (UTS), Australia. His research interests include design optimization and control of electrical drive systems and renewable energy

systems

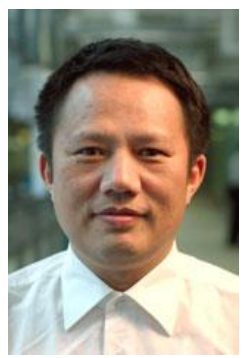

Youguang Guo (S'02-M'05-SM'06) received the B.E. degree from Huazhong University of Science and Technology, China in 1985, the M.E. degree from Zhejiang University, China in 1988, and the Ph.D. degree from University of Technology, Sydney (UTS), Australia in 2004, all in electrical engineering. $\mathrm{He}$ is currently an associate professor at the School of Electrical and Data Engineering, University of Technology Sydney (UTS). His research fields include measurement and modeling of properties of magnetic materials, numerical analysis of electromagnetic field, electrical machine design optimization, power electronic drives and control.

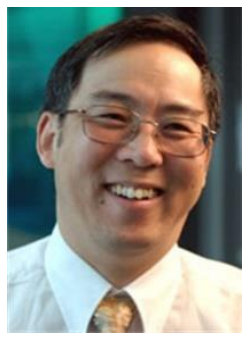

Jianguo Zhu (S'93-M'96-SM'03) received the B.E. degree in 1982 from Jiangsu Institute of Technology, Jiangsu, China, the M.E. degree in 1987 from Shanghai University of Technology, Shanghai, China, and the Ph.D. degree in 1995 from the University of Technology Sydney (UTS), Sydney, Australia, all in electrical engineering. $\mathrm{He}$ was appointed a lecturer at UTS in 1994 and promoted to full professor in 2004 and Distinguished Professor of Electrical Engineering in 2017. At UTS, he has held various leadership positions, including the Head of School for School of Electrical, Mechanical and Mechatronic Systems and Director for Centre of Electrical Machines and Power Electronics. In 2018, he joined the University of Sydney, Australia, as a full professor and Head of School for School of Electrical and Information Engineering. His research interests include computational electromagnetics, measurement and modelling of magnetic properties of materials, electrical machines and drives, power electronics, renewable energy systems and smart micro grids. 